\title{
Modeling perspectives on the mid-Pleistocene transition
}

\author{
Matteo Willeit and Andrey Ganopolski
}

\begin{abstract}
Model simulations reveal the importance of atmospheric $\mathrm{CO}_{2}$ and glacial erosion for Quaternary climate dynamics, in particular for the transition from glacial cycles with a periodicity of 40,000-year to 100,000-year cycles at around 1 million years ago.
\end{abstract}

The Quaternary is the most recent geological period, covering the past $\sim 2.6$ million years. It is characterized by the presence of glacial-interglacial cycles associated with the cyclic growth and decay of continental ice sheets in the Northern Hemisphere. Climate variations during the Quaternary are best seen in oxygen isotopes measured in deepsea sediment cores, which represent variations in global ice volume and ocean temperature (Lisiecki and Raymo 2005). These data show clearly that there has been a general trend towards larger ice sheets and cooler temperatures over the last 3 million years, accompanied by an increase in the amplitude of glacial-interglacial variations and a transition from mostly symmetrical cycles with a periodicity of 40,000 years ( 40 kyr) to strongly asymmetric $100-$ kyr cycles at around 1 million years ago (Fig. 1a). The ultimate causes of these transitions in glacial cycle dynamics still remain debated.

The role of atmospheric $\mathrm{CO}_{2}$ changes in shaping Quaternary climate dynamics is not yet fully understood, largely because of the poor observational constraints on atmospheric $\mathrm{CO}_{2}$ concentrations for the time prior to $800 \mathrm{kyr}$ before present (BP), beyond the period covered by high-quality ice-core data. Proxy-based reconstructions suggest that, over the past $\sim 2$ million years, $\mathrm{CO}_{2}$ did not significantly deviate from the range of concentrations measured in ice cores, but that it was substantially higher during the late Pliocene (e.g. Hönisch et al. 2009; Martínez-Botí et al. 2015). A long-term cooling trend associated with a decrease in atmospheric $\mathrm{CO}_{2}$ concentration has been invoked as a possible mechanism to explain the glaciation of Greenland and more generally the Northern Hemisphere at around 3 million years ago (Lunt et al. 2008; Willeit et al. 2015).

It has also been suggested that Northern Hemisphere continents were all covered by thick terrestrial sediments before the Quaternary, an expected outcome of the tens of millions of years that the bedrock was exposed to weathering before the initiation of glacial cycles. The observed present-day sediment distribution, which is characterized by exposed bedrock over large parts of northern North America and Eurasia, is a result of glacial erosion by Quaternary ice sheets. It has been proposed that gradual removal of the sediment layer by glacial erosion could have changed the ice sheets' response to orbital forcing (Clark and Pollard 1998).

\section{Modeling natural climate variability of the past 3 million years}

We have used the simplified Earth system model CLIMBER-2 to elucidate the drivers behind the transitions in glacial cycles of the Quaternary (Willeit et al. 2019). Besides the ocean and atmosphere, the model includes a dynamic vegetation module, interactive ice sheets for the Northern Hemisphere, and a fully coupled global carbon cycle, allowing us to interactively simulate atmospheric $\mathrm{CO}_{2}$ (Ganopolski and Brovkin 2017). The model was driven only by changes in the
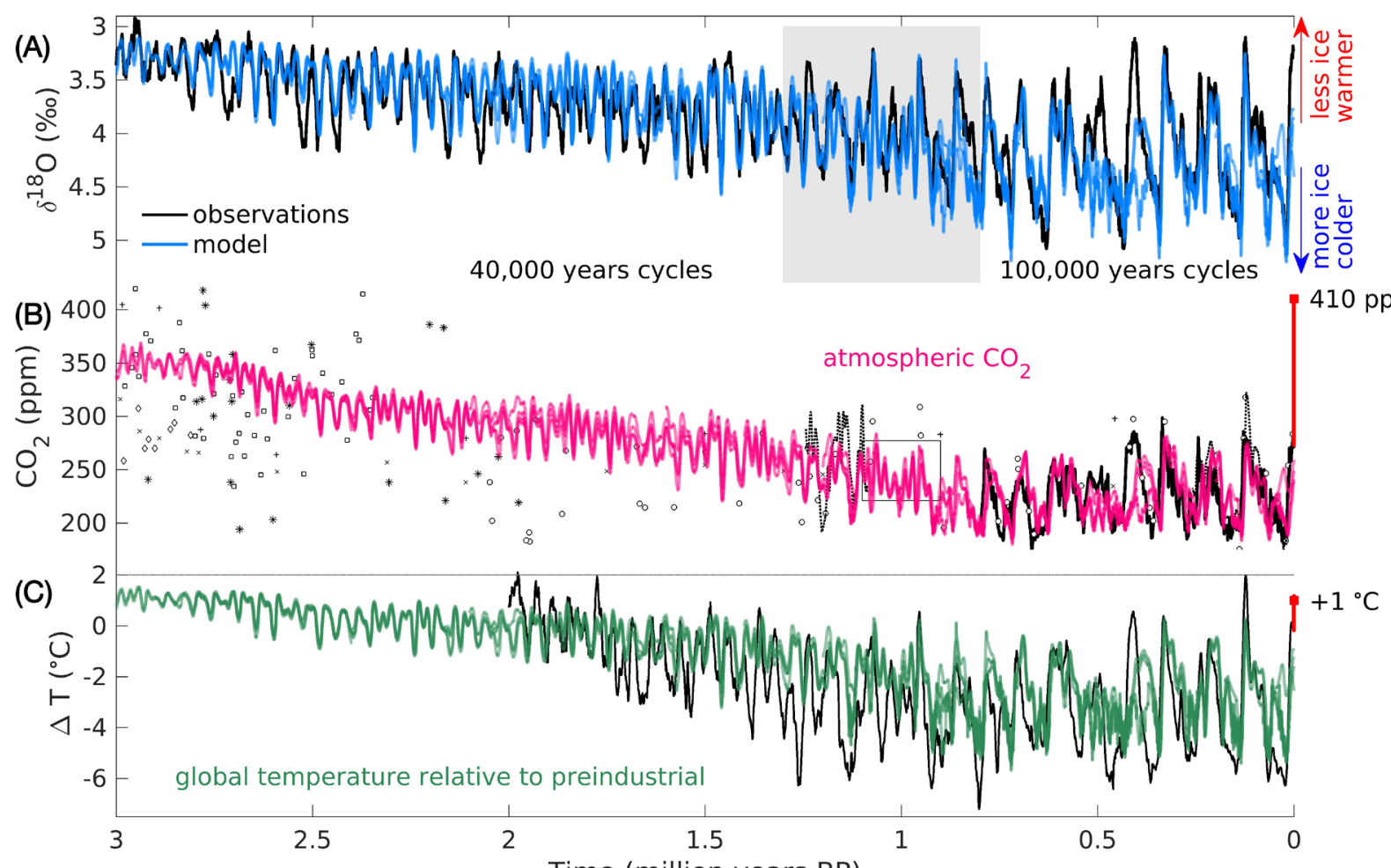

Time (million years BP)

Figure 1: (A) Comparison of modeled and observed (Lisiecki and Raymo 2005) stable oxygen isotopes in deep sediment cores over the last 3 million years. The grey shaded area indicates the period characterized by the transition from glacial cycles with a period of $40 \mathrm{kyr}$ to cycles with a period of $100 \mathrm{kyr}$. Modeled benthic $\delta^{18} \mathrm{O}$ is estimated from the modeled sea level, $\mathrm{z}_{\mathrm{SL}}$, and deep ocean temperature, $\mathrm{Td}$, as follows: $\delta^{18} \mathrm{O}=4.0-0.22 \mathrm{Td}-0.01 \mathrm{z}_{\mathrm{SL}}$. (B) Modeled atmospheric $\mathrm{CO}_{2}$ concentration compared with ice-core data (solid black line; Bereiter et al. 2015) and various proxy reconstructions (symbols and dotted line, circles: Hönisch et al. 2009; squares: Martínez-Botí et al. 2015; *: Bartoli et al. 2011; + and x: Seki et al. 2010; diamonds: Badger et al. 2013; black box: Higgins et al. 2015; dotted lines: Chalk et al. 2017). The red line represents the observed CO 2 increase since the beginning of the industrial revolution and the red square indicates the observed value at the end of 2018. (C) Modeled global temperature relative to preindustrial compared with reconstructions (Snyder 2016). The red line and square indicate the temperature increase of $\sim 1^{\circ} \mathrm{C}$ since preindustrial. 
(A) CLIMBER-2

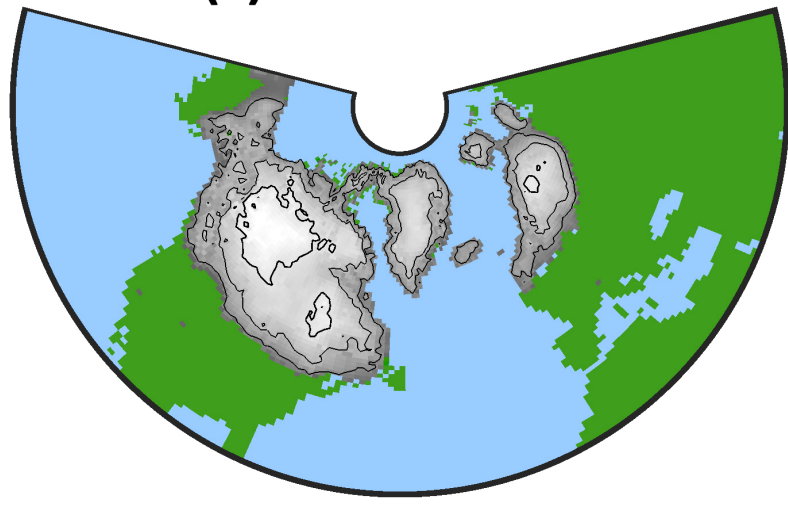

(B) GLAC-1D

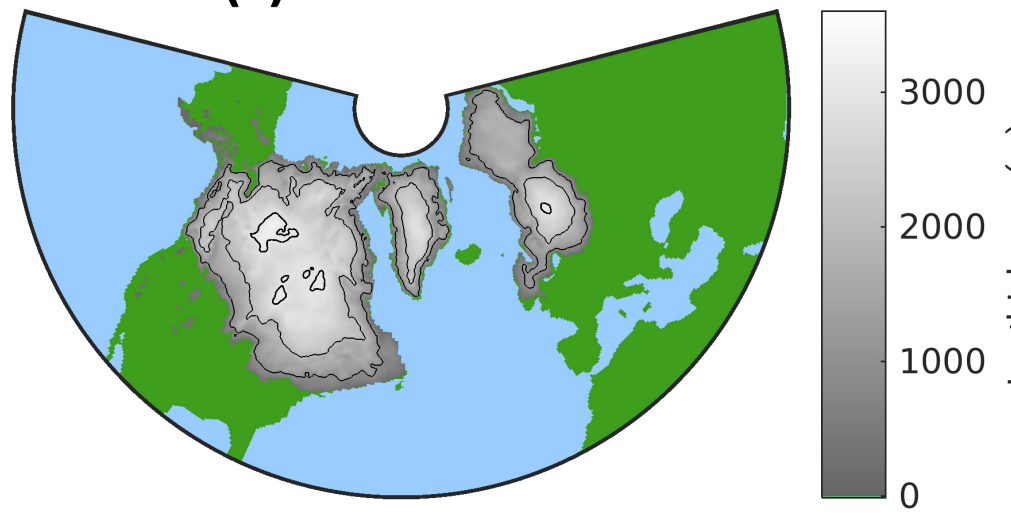

Figure 2: Comparison of the ice-sheet extent and thickness at the Last Glacial Maximum (21 kyr BP) from (A) the CLIMBER-2 model (Willeit et al. 2019 ) with (B) the modelbased reconstruction of Tarasov et al. (2012).

orbital configuration and different scenarios for slowly varying boundary conditions, including $\mathrm{CO}_{2}$ outgassing from volcanoes as a geologic source of $\mathrm{CO}_{2}$, and changes in sediment distribution over the continents. Antarctica is prescribed at its present state in the model, but its effect on sea level is accounted for, to a first approximation, by assuming an additional $10 \%$ contribution from Antarctica on top of sea-level variations from simulated changes in Northern Hemisphere ice volume.

When the model is driven by orbital variations and optimal sediment distribution and volcanic outgassing scenarios, it reproduces the evolution of many reconstructed characteristics of Quaternary glacial cycles. It simulates most of the details of the observed oxygen isotope $\delta^{18} \mathrm{O}$ curve (Fig. 1a), including long-term trends and glacial-interglacial variability. The relative contribution of deep-sea temperature and sea-level variations to $\delta^{18} \mathrm{O}$ variability changes substantially through time, with temperature variations more important during the early Quaternary, and sea-level variations dominating the signal during the late Quaternary. The model also captures the secular cooling trend of approximately $-1{ }^{\circ} \mathrm{C} /$ million years in sea surface temperatures. The intensification of Northern Hemisphere glaciation after $\sim 2.7$ million years ago is marked by a rather abrupt increase in global ice-volume variations and an increase in iceberg flux from the Laurentide ice sheet into the North Atlantic, in good agreement with a proxy for ice-rafted debris. Interglacial atmospheric $\mathrm{CO}_{2}$ concentrations decrease from values of $\sim 350$ parts per million ( $\mathrm{ppm}$ ) during the late Pliocene to values between 260 and 290 ppm, typical of the past 800,000 years, at $\sim 1$ million years ago (Fig. 1b). The amplitude of glacial-interglacial $\mathrm{CO}_{2}$ variations increases from $\sim 50 \mathrm{ppm}$ at the beginning of the Quaternary to $\sim 80$ to $90 \mathrm{ppm}$ during the 100 -kyr cycles of the past million years.

\section{Initiation of NH glaciation and transition from 40- to 100-kyr cycles}

Our results imply a strong sensitivity of the Earth system to relatively small variations in atmospheric $\mathrm{CO}_{2}$. A gradual decrease of $\mathrm{CO}_{2}$ to values below $\sim 350 \mathrm{ppm}$ led to the start of continental ice-sheet growth over Greenland and more generally over the Northern Hemisphere at the end of the Pliocene and beginning of the Pleistocene, around 2.7 million years ago. Subsequently, the waxing and waning of the ice sheets acted to gradually remove the thick layer of unconsolidated terrestrial sediments that had been formed previously over continents by the undisturbed action of weathering over millions of years. The erosion of this sediment layer - it was essentially bulldozed away by moving glaciers - affected the evolution of glacial cycles in several ways. First, ice sheets sitting on soft sediments are generally more mobile and thinner than ice sheets grounded on hard bedrock, because ice slides more easily over sediments compared to bedrock. This makes ice sheets more vulnerable to increasing summer insolation and thus facilitates their retreat. Additionally, glacial sediment transport to the ice-sheet margins generates substantial amounts of dust that, once deposited on the ice-sheet surface, increases melting of the ice sheets by lowering surface albedo. Model results show that the gradual increase in the area of exposed bedrock over time led to more stable ice sheets, which were less responsive to orbital forcing and ultimately paved the way for the transition to 100 -kyr cycles at around 1 million years ago.

\section{Putting the results into present- \\ day and future perspectives}

Our simulations further suggest that global temperature never exceeded the preindustrial value by more than $2^{\circ} \mathrm{C}$ during the Quaternary (Fig. 1c). Ice-sheet evolution is very sensitive to temperature, and the initiation of Northern Hemisphere glaciation at around 3 million years ago would not have been possible in the model if global temperature were to have been higher than $2^{\circ} \mathrm{C}$ relative to preindustrial during the early Quaternary. Since the model has been shown to accurately reproduce the sea-level variations over the last $400 \mathrm{kyr}$ and also the spatial ice-sheet distribution at the last glacial maximum (Fig. 2), we are confident that the sensitivity of ice sheets to climate is well represented in the model.

Likewise, our results indicate that the measured $\mathrm{CO}_{2}$ concentration of $\sim 410 \mathrm{ppm}$ at the end of 2018 is unprecedented over the past 3 million years. The climate sensitivity of the model is around $3^{\circ} \mathrm{C}$ global warming for a doubling of $\mathrm{CO}_{2}$ concentration. This falls in the middle of the current best estimates of climate sensitivity, which range between 1.5 and $4.5^{\circ} \mathrm{C}$. It is theoretically possible that the real climate sensitivity is lower than $3^{\circ} \mathrm{C}$, in which case the modeled $\mathrm{CO}_{2}$ concentration needed to fit the oxygen isotope record during the early Quaternary would be higher than in the present model simulations, but it would still be unlikely to exceed the presentday value.

In the context of future climate change, our results imply that a failure to significantly reduce $\mathrm{CO}_{2}$ emissions to comply with the Paris Agreement target of limiting global warming well below $2^{\circ} \mathrm{C}$ will not only bring Earth's climate away from Holocene-like conditions, but also push it beyond climatic conditions experienced during the entire current geological Period, the Quaternary.

\section{AFFILIATION}

Potsdam Institute for Climate Impact Research, Germany

\section{CONTACT}

Matteo Willeit: willeit@pik-potsdam.de

\section{REFERENCES}

Badger MPS et al. (2013) Philos T R Soc A 371: 20130094 Bartoli G et al. (2011) Paleoceanography 26: PA4213 Bereiter B et al. (2015) Geophys Res Lett 42: 542-549 Chalk TB et al. (2017) Proc Natl Acad Sci 114: 13114-13119 Clark PU, Pollard D (1998) Paleoceanography 13: 1-9 Ganopolski A, Brovkin V (2017) Clim Past 13: 1695-1716 Higgins JA et al. (2015) Proc Natl Acad Sci 112: 6887-6891 Hönisch B et al. (2009) Science 324: 1551-1554

Lisiecki LE, Raymo ME (2005) Paleoceanography 20: 1-17 Lunt DJ et al. (2008) Nature 454:, 1102-1105 Martínez-Botí MA et al. (2015) Nature 518: 49-54 Seki O et al. (2010) Earth Planet Sc Lett 292: 201-211 Snyder CW (2016) Nature 538: 226-228

Tarasov L et al. (2012) Earth Planet Sc Lett 315-316: 30-40 Willeit M et al. (2015) Quat Sci Rev 119: 22-34 Willeit M et al. (2019) Sci Adv 5: eaav7337 